\title{
The roles and role-players in thyroid cancer angiogenesis
}

\author{
Sadegh Rajabi ${ }^{1)}$, Mohammad Hossein Dehghan ${ }^{2)}$, Romina Dastmalchi ${ }^{3)}$, Farideh Jalali Mashayekhi' ${ }^{4}$, \\ Siamak Salami ${ }^{1)}$ and Mehdi Hedayati ${ }^{5)}$ \\ 1) Department of Clinical Biochemistry, School of Medicine, Shahid Beheshti University of Medical Sciences, Tehran, Iran \\ 2) Biochemistry Department, School of Medicine, Alborz University of Medical Sciences, Karaj, Iran \\ 3) Department of Medical Genetics, Shahid Beheshti University of Medical Sciences, Tehran, Iran \\ 4) Department of Biochemistry and Genetics, Arak University of Medical Sciences, Arak, Iran \\ 5) Cellular and Molecular Endocrine Research Center, Research Institute for Endocrine Sciences, Shahid Beheshti University of \\ Medical Sciences, Tehran, Iran
}

\begin{abstract}
Thyroid cancer is the most prevalent endocrine cancer worldwide. Angiogenesis, the formation of new blood vessels, plays a pivotal role in the development and progression of tumors. Over the past years, cancer research has focused on the ability of tumors to induce newly formed blood vessel, because tumor growth and the process of cancer metastasis mainly depends on angiogenesis. Tumor neovascularization occurs following the imbalance between pro-angiogenic and antiangiogenic factors until the tumor switches to an angiogenic phenotype. A number of signaling factors and receptors that are implicated in the regulation of angiogenesis have been identified and characterized; most notably, the vascular endothelial growth factors (VEGFs) family and their receptors, which are the main pro-angiogenic molecules during early development and in pathological conditions such as cancer. Although thyroid is a highly vascularized organ, angiogenic switch in tumors of this organ leads to the formation of a vast network of blood vessels that favors the dissemination of tumor cells to distant organs and results in deterioration of patient conditions. Accordingly, the identification of key angiogenic biomarkers for thyroid cancer can facilitate diagnosis, prognosis and clinical decision-making and also may help to discover targeting factors for effective cancer therapy as well as monitoring response to therapy. Hence, the main purposes of this review are to summarize the types and mechanisms of angiogenesis emphasizing the prominent factors implicated in thyroid cancer angiogenesis.
\end{abstract}

Key words: Thyroid cancer, Biomarker, Angiogenesis, Metastasis

\section{Introduction}

Thyroid cancer is the most prevalent endocrine cancers, with an estimated incidence of 12.2 cases per 100,000 people per year in the United States [1]. This type of cancer occurs with various biological behaviors, ranging from indolent, well-differentiated tumors to highly aggressive, poorly differentiated or anaplastic tumors [2]. Growth of a malignant tumor critically depends on the extent of blood vessels providing a sufficient supply of

Submitted Dec. 8, 2018; Accepted Feb. 1, 2019 as EJ18-0537 Released online in J-STAGE as advance publication Mar. 6, 2019 Correspondence to: Mehdi Hedayati, Cellular and Molecular Endocrine Research Center, Research Institute for Endocrine Sciences, Shahid Beheshti University of Medical Sciences, No 24, Parvaneh St, Velenjak, Tehran 198571741, Iran.

E-mail: hedayati47@yahoo.com

Correspondence to: Siamak Salami, Department of Clinical Biochemistry, School of Medicine, Shahid Beheshti University of Medical Sciences, No 28, Kodakyar St, Velenjak, Tehran 198571741, Iran.

E-mail: Salami.si@gmail.com oxygen and nutrients along with the removal of waste products. Moreover, the formation of the new blood vessels plays an important role in metastatic spread to another organ [3]. According to scientists opinion, Ide, et $a l$. were the first researchers that introduced the concept of angiogenesis in the tumor. They indicated that the implantation of tumor tissues in the ears of rabbits was accompanied by the formation of new capillaries suggesting the idea that angiogenesis is obligatory to support malignant tumor growth [4]. Two years later, Harry Green also showed that the growth of rabbit tumors transplanted into the anterior chamber of the eyes of guinea pigs had been accompanied by the growth of new blood vessels [5]. However, about 30 years later, Judah Folkman started a systematic study to think about cancer in a revolutionary new way. He assumed that malignant tumors need blood vessels to survive and grow, and the disruption of such vessels could result in cancer starvation and remission [6, 7]. Indeed, Folkman's pioneering study led him and others to understand the response of tumors to hypoxia, which can initiate angiogenesis and 
tumor growth [8]. It is well-known that angiogenesis occurs during the embryonic period and remains, with less extent, during adulthood [9]. Angiogenic activity has been shown to be crucial to thyroid cancer progression [10]. Accordingly, in recent years many efforts have been devoted to investigate and present the suitable biomarkers of thyroid angiogenesis [11]. Biomarkers are commonly involved in biological processes such as angiogenesis, differentiation, and growth. Thus, dysregulation of these biomarkers could result in cancer initiation, progression, and metastasis. It has been noted that these biological factors could be used as diagnostic, prognostic and therapeutic markers. Identification of important cancer biomarkers also sheds light on novel approaches in cancer therapy [12]. Hence, the main purposes of this review are to summarize the types and mechanisms of angiogenesis emphasizing the prominent factors implicated in thyroid cancer angiogenesis.

\section{Thyroid Vascular Supply}

Thyroid as an important part of endocrine system that directly releases hormones to the blood circulation has to be highly vascularized. Two major arteries supply the thyroid gland: 1) The superior thyroid artery that reaches to the superior pole of the lateral lobe of the gland where it divides into anterior and posterior glandular branches; 2) The inferior thyroid artery that supplies the inferior pole of the lateral lobe of the thyroid gland and divides into an: inferior branch, which supplies the lower part of the thyroid gland; and an ascending branch, which drains the parathyroid glands. Occasionally, a small thyroid ima artery also reaches the thyroid gland. Thyroid has three veins, namely the superior, the middle and inferior thyroid veins. Lymphatic vessels of the thyroid gland drain paratracheal and cervical nodes [13].

\section{The Process of Angiogenesis}

In the course of embryogenesis, neovascularization takes place in two different ways, including vasculogenesis, the de novo formation of new vessels from endothelial cell progenitors occurring in embryogenesis, and angiogenesis, as the sprouting of new vessels from existing ones. In the adults, angiogenesis can occur only transiently as part of physiologic processes such as wound healing and female reproductive cycling [14-17]. Accordingly, embryonic vascular network development is required to provide oxygen and nutrients for the fetus, while physiological angiogenesis in the adults occurs in response to the metabolic demands of tissues and is effectively triggered by hypoxia [18]. During embryogenesis, mesenchymal cells differentiate into angioblasts, which are precursors of endothelial and hematopoietic cells from mesodermal tissues [19]. Angioblasts have the ability to migrate through the embryo and differentiate into endothelial cells forming vessel walls [20]. Because the thyroid gland is a highly vascularized gland, impaired angiogenesis during embryo development may lead to thyroid dysfunction [21]. Fetal angiogenic factors such as placental growth factor (P1GF) vascular endothelial growth factor (VEGF) and soluble FMS-like tyrosine kinase-1 (sFlt1) have been shown to affect thyroid function and vascular density [22]. It is noted that the vasculature of solid tumors is remarkably distinct from that of normal vasculature. For example, blood vessels that supply tumor tissue have irregular size and disorganized arrangement, where they simultaneously share features of arterioles, capillaries, and venules [23]. In normal tissue vessels, metabolic requirements of cells determine the blood flow and density of the vessels, but in tumor tissues, the blood flow appears to be sporadic, which can lead to damaged capillary network systems [24, 25]. During the aforementioned physiologic processes, there is an intricate balance between pro- and anti-angiogenic signals that are strongly maintained, leading to provide maturity and stability for newly formed vessels. However, tumor-related angiogenesis is shown a disrupted balance between these angiogenic factors, allowing unlimited development of blood vessels. This abnormal shift could result in an alteration in normal vasculature characteristics including their physical properties [26]. Tumor neovascularization has been classified into five types:1) Angiogenesis; 2) Vasculogenesis; 3) Vascular remodeling: intussusceptive or splitting vascular growth is defined as the insertion of interstitial tissue columns into the vascular lumen and subsequent growth of these columns leading to the partitioning of the vessel lumen. In this type of neovascularization, endothelial cell division is not needed; 4) Glomeruloid angiogenesis is the formation of highly complex vascular structures that are similar to glomeruli of the kidney; 5) Vascular mimicry, referring to the ability of tumor cells to form a complete capillary network composed of neoplasm cells themselves without vascular endothelial cells that conduct blood [27]. However, some studies have described two main types of the angiogenesis: sprouting, which is the expansive growth of new capillary vessels out of preexisting ones the and intussusceptive (splitting) angiogenesis, which is defined as the rebuild of the blood vessel network [28, 29]. More interestingly, Benest, et al. described another form of angiogenesis termed looping angiogenesis, which is involved in the special requirements of wound healing [30]. Fig. 1 shows different types of tumor neovascularization. It is noteworthy to mention that the type of angiogenesis in a certain tissue 


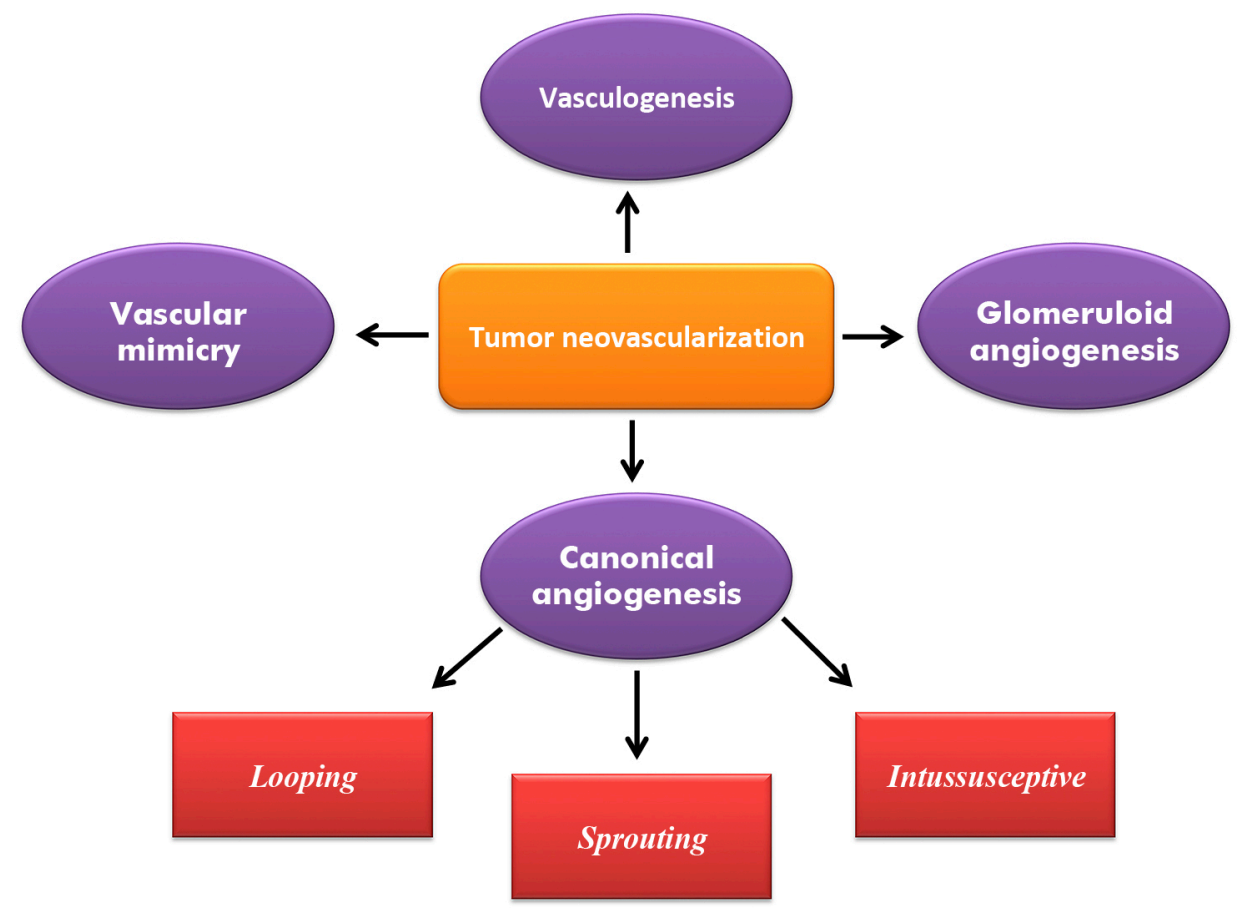

Fig. 1 Diagram illustrating different types of tumor angiogenesis

or organ depends upon the number of vessels already present during the initiation of the fast development of the organ or the tumor [31]. The process of angiogenesis is composed of several steps: 1) Activation of the endothelial cells, which is accompanied by overexpression of receptors such as VEGF receptors and $\alpha \mathrm{v} \beta 3$ and $\alpha \mathrm{v} \beta 5$ integrins etc. Degradation of vascular basement membrane and of the extracellular matrix, by matrix metalloproteinases (MMPs) and the plasminogen pathway, also occur in this step; 2) The proliferation and migration of activated endothelial cells into interstitium leading to endothelial tube formation; 3) Differentiation of endothelial cells; 4) Synthesis of new basal membrane and the maturation of new vessels accompanied by vascular lumen formation [32-34].

\section{Types of tumor angiogenesis}

Tumor angiogenesis, as a fast growing process, is an important event in tumor biology. For about three decades, the sprouting angiogenesis originating from existing vessels was considered as an only way of tumor vascularization. However, in recent years some other mechanisms have been identified [35]. On the other hand, before the publications by Caduff, et al. [36] and Burri and Tarek [37] on blood vessel formation by intussusception, the sprouting model was the first known mechanism of angiogenesis. They find this new mechanism when they were studying the transformation of the capillary network in the respiratory systems of postnatal rats and humans during the investigating of postnatal lung devel- opment $[36,38]$. It has been totally accepted that angiogenesis occurs mainly through sprouting angiogenesis together with some degree of the intussusceptive mechanism [39, 40]. However, more recently, another form of tumor angiogenesis called looping angiogenesis has been revealed to occur in a non-developmental context [41].

\section{Sprouting angiogenesis}

Sprouting angiogenesis is the oldest described mechanism of angiogenesis [42]. Our knowledge of sprouting angiogenesis is originally based on results obtained from many developmental models, such as mouse and zebrafish models as well as CAM and advanced 3D in-vitro models [43-47]. According to some investigations, sprouting angiogenesis is started in poorly perfused tissues when terminal branches of the existing vessels, which serve as oxygen sensors, detect some degree of hypoxia that demands the formation of new blood vessels to provide the metabolic requirements of the tissue cells $[48,49]$. In cancerous tissues, sprouting angiogenesis is not only implicated in primary tumors, but it also has a crucial role in the formation of metastasis and further outgrowth of metastases [14]. The process of sprouting angiogenesis is similar to the multi-step mechanism of angiogenesis mentioned above. Initiation of capillary sprouting is triggered by proangiogenic chemokines and cytokines, leading pericytes to detach from the vessel wall. Then, plasma proteins leave the vessel to form a temporary extracellular matrix, which has several roles, including cells migration guidance, storing proangiogenic molecules such as VEGF, fibroblast growth factors 
(FGFs) and promoting synergistic signaling with integrins [50, 51]. Subsequently, the release of growth factors during proteolytic degradation and remodeling of the temporary matrix leads to proliferation and migration of endothelial cells [52]. In developmental sprouting angiogenesis, branching guidance is under the control of expressed genes in the newly formed tissue, whereas guidance of sprouts in tumor context is supervised by the gradient of secreted factors in the tumor microenvironment [53-55]. It is postulated that VEGF is a key factor that plays a central role in the morphology of vessels during sprouting angiogenesis. Notably, the gradient of this factor can regulate the migration of tip cells, a subset of endothelial cells as leading cells at the tips of sprouts, and the proliferation of stalk cells, which move behind the tip cells, in a polarized manner $[43,56]$. VEGFs and VEGFRs signaling represent one of the best-validated and most investigated molecular pathways in angiogenesis [57]. There are several isoforms of VEGFs and VEGFRs (Fig. 2). VEGF gene family comprises six different isoforms, including VEGFA, VEGF-B, VEGF-C, VEGF-D, VEGF-E and placental growth factor (PIGF) [58]. All these VEGF molecules bind to three different receptor tyrosine kinases termed VEGFR-1, VEGFR-2, and VEGFR-3 [59]. Some VEGF family members also bind to non-tyrosine kinase receptors called neuropilin (NRP) family, NRP-1 and NRP-2, which are known as co-receptors for the VEGFRs [60]. VEGFR-1, VEGFR-2, NRP-1, and NRP-2 have binding sites for VEGFA; VEGF-B binds to VEGFR-1 and NRP-1; PIGF interacts with VEGFR-1, NRP-2, and NRP-1; and VEGF-C and VEGF-D bind to VEGFR-3, VEGFR-2, NRP-1 and NRP-2 [61]. It is discovered that VEGF members have been also involved in lymphangiogenesis (generation of lymphatic vessels), hematopoiesis, recruitment of monocytes during inflammation or infection, and proliferation or survival of other cell types expressing VEGFRs or NRPs [62-65]. VEGF/VEGFR signaling pathway triggers cascades such as Mitogen-activated protein kinase (MAPK) pathway, phosphoinositide 3kinase (PI3K) pathway, Phospholipase C-gamma (PLC$\gamma)$ pathway, and endothelial nitric oxide synthase (eNOS) signaling to exert their effects $[66,67]$. As noted earlier, the hypoxic environment induces the angiogenesis. It is documented that hypoxia can stimulate parenchymal cell of the tissues to secret VEGF-A (also known as VEGF) as a key proangiogenic factor that there appears to be a completely unique factor in hypoxia-induced angiogenesis [68-70]. It is also clear that the tip cell guides the developing vessel sprout through extracellular matrix toward VEGF-A gradient [49, 69]. Delta-Notch signaling pathway and its ligand, Delta-like-4 (Dll4), have an essential role in sprout formation. Interestingly, VEGF-A has been reported to induce the production of D114 by tip cells leading to inhibition of disorganized sprout formation [71-73].

\section{Intussusceptive angiogenesis}

Sprouting model is a time consuming and energy intensive mechanism of angiogenesis. Thus, nature has developed a more rapid way termed intussusceptive angiogenesis to create new vessels [74]. Intussusceptive angiogenesis mechanism occurs by longitudinal splitting of existing vasculature into two functional vessels [75]. This type of angiogenesis was first described by Caduff, et al. in 1986 when they were studying the pulmonary capillary bed of newborn rats using electron microscopy [76]. According to results of one study, application of VEGF-A in the chick chorioallantoic membrane (CAM) could result in stimulation of intussusceptive angiogenesis in the capillary plexus and terminal feeding vessels of this membrane. These authors have also concluded that high levels of VEGF can induce endothelial cells that undergo intussusceptive angiogenesis to either sprout or fuse or maybe even both [77]. The process of intussusceptive angiogenesis includes four steps: 1) Intussusceptive endothelial cells opposite from one another within the capillary wall migrate to each other to form a transluminal pillar; 2) After initial contact, rearrangement of endothelial cells forms a central perforation in the core of the pillar forming a cylindrical bridge in the central part of the vessel; 3) Central pillars are invaded by pericytes and myofibroblasts to form an ECM in pillars; 4) Finally, the pillars increase in size and being mature to split up the initial capillary into two new one [78]. Although intussusceptive angiogenesis was discovered in developing lungs, many reports indicated that this type of angiogenesis also occurs in wide range of other tissues, including muscle, bone, kidney, retina, mammary gland, ovary and many more [79-85]. This type of angiogenesis has been reported in some tumor tissues such as breast tumors, colon tumors, gliomas, hepatocellular carcinomas [86-89]. There is some evidence indicating the escape mechanism after antiangiogenic therapy using vandetanib (a tyrosine kinase inhibitor) combined with ionizing radiation [90, 91]. Results of these studies showed that this type of combination therapy could result in an angiogenic switch from sprouting to intussusceptive angiogenesis, representing an escape mechanism and resistance of the tumor to treatment. Makanya, et al. studied the interplay between sprouting and intussusceptive vascular growth modes in the development of the microvascular network in the chicken embryo lung and kidney $[92,93]$. In one study, they found that high expression of VEGF was related to sprouting mode of angiogenesis, whereas, strong expression of FGF was observed in the intussusceptive form of angiogenesis 


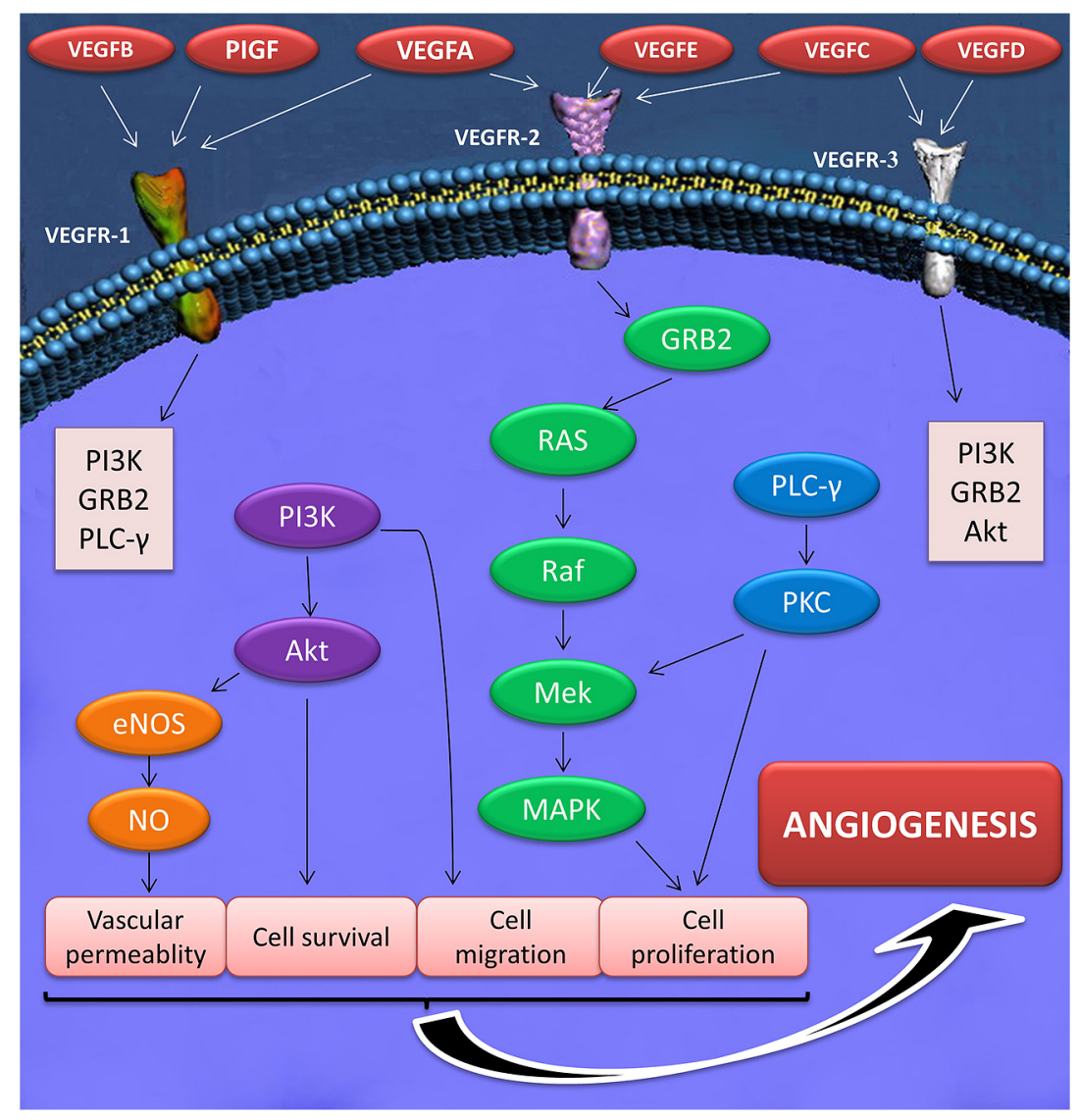

Fig. 2 VEGF family and their respective receptors

[92]. In another study, they showed that the expression of VEGF-A and FGF were maintained at moderate levels during the sprouting phase of angiogenesis, while Platelet-derived growth factor-B (PDGF-B) expression was minimal. However, the expression levels of all three factors were increased during intussusceptive angiogenesis [93]. Together, it appears that the intussusceptive angiogenesis does not directly need endothelial cell proliferation and as mentioned above, migration and rearrangement of endothelial cells of the existing vessel can provide new vessel network. Thus, it can be acceptable that this type of angiogenesis is not or less dependent on proliferative pathways such as the VEGF signaling pathway and that the VEGF inhibitors do not appear to hamper the tumor growth.

\section{Looping angiogenesis}

As mentioned earlier, looping angiogenesis is a form of angiogenesis process that is involved in special requirements of wound healing [30, 94, 95]. Although looping Angiogenesis has been observed in several nondevelopmental settings [96], there is an emerging body of evidence showing that this type of angiogenesis occurs in tissue revascularization in post-developmental settings. Namely, the process was indicated to be the main mechanism of wound vascularization in human surgical wounds [97]. This type of angiogenesis is not regulated by traditional way involving pericytes and endothelial cell, but rather by contractile myofibroblasts that pull the extracellular matrix and adjacent tissue into the wound area, resulting in elongation of vessels and the vascular loops formation. Thus, loop-shape expansion of the vessel by lopping angiogenesis is a mechanical mode of neovascularization that there appear to be less dependent on signaling pathways such as the VEGF pathway [95]. However, Maes, et al. recently suggested that during endochondral development, interactions of osteoblastic precursors with the endothelium may cause the invasion of mature vessels into the cartilage, probably via both looping and sprouting angiogenesis mechanisms [98]. More interestingly, they also proposed that cartilage vascularization may steer by the high levels of stimulatory factors, including VEGFs. Although looping angiogenesis process has not been fully understood and has not yet been indicated to be a pivotal angiogenic process implicated in vessel growth during tumor vascular development, there are multiple pieces of evidence indicating the relation between tumor neovascularization and wound healing. Notably, tumors have formerly been described as "wounds that do not heal" [99]. In addition, identification of hypoxic tumor cell areas in squamous 
cell carcinomas of the uterine cervix showed the evidence of looping angiogenesis, which was clearly visible as a finger-like protrusion that was pulled into the direction of the hypoxic center of a tumor cell aggregate [100]. The results obtained from time-lapse intravital multiphoton microscopy showed that the mechanical forces in rapidly growing tumors could extend the vessels in a process that could be considered as looping angiogenesis, which may occur with other types of angiogenesis [101].

\section{Mechanism of Control of Angiogenesis}

It is now clear that the angiogenic activity of tumor tissue is a result of the net balance between pro- and antiangiogenic factors [102]. To date, several stimulatory and inhibitory regulators of angiogenesis have been identified (Table 1). The proportion of these opposite factors determines the angiogenic behavior of the tumor. When stimulatory factors are produced in excess of inhibitory factors, the balance is in favor of vessel expansion. On the contrary, when inhibitory factors are dominant, angiogenic activity is ceased [102-104]. It is acceptable that the up-regulation of a stimulatory growth factor is not sufficient for tumor angiogenesis, but rather the down-regulation of certain inhibitory regulators may be necessary for vessel growth [105]. However, the scenario appears to be much more complex than it at first seems. There are some other molecular mechanisms implicated in vascularization of the tumor. For example, some oncogenes, including c-Met down-regulates thrombospondin-1 (TSP-1), leading to angiogenesis and tumor progression [106]. Moreover, there are multiple oncogenes such as ras, raf, src, and erbB2, which positively regulate the expression of VEGF [107-110]. Otherwise, tumor suppressors such as von Hippel-Lindau (VHL) negatively regulate the expression of VEGF [111]. p53, as a transcription factor involved in the checkpoint of the cell cycle, can act as a tumor suppressor by activating the promoter of TSP-1 [112]. The most important factor that controls blood vessel growth is VEGF, particularly, VEGF-A, which is pivotal for many aspects of the angiogenesis being equally prominent for blood vessel development in adults and tumors [113]. VEGF also stimulates integrin $\alpha v \beta 3$ to promote both neovascularization and tumor cell invasion via ECM through paracrine and autocrine regulatory mechanisms $[114,115]$. FGF, as a potent angiogenic inducer, has different in control of neovascularization by interaction with other growth factors and chemokines such as VEGF, hepatocyte growth factor (HGF), PDGF, and Monocyte chemoattractant protein-1 (MCP-1). However, it appears that the unique role of this factor is the organi-
Table 1 Different stimulatory and inhibitory regulators of angiogenesis

\begin{tabular}{|c|c|}
\hline Stimulators & Inhibitors \\
\hline VEGFs & Angiostatin \\
\hline FGF & Anti-angiogenic anti-thrombin III \\
\hline MMPs & TIMPs \\
\hline PDGF & Vasostatin (calreticulin fragment) \\
\hline Angiopoietin-1 & Canstatin \\
\hline $\mathrm{HGF}$ & Endostatin (collagen XIII fragment) \\
\hline Leptin & Fibronectin fragment \\
\hline MCP-1 & Heparinases \\
\hline$\beta$-Estradiol & IFN- $\alpha, \beta, \gamma$ \\
\hline NOS & IL4, IL12, IL18 \\
\hline IL-8, IL-1 & Plasminogen activator inhibitor \\
\hline TNF- $\alpha$ & PEDF \\
\hline Angiogenin & Prolactin $16 \mathrm{kDa}$ fragment \\
\hline $\mathrm{TGF}-\alpha / \beta$ & TSP-1 \\
\hline Ephrins & Retinoids \\
\hline integrins $\alpha \mathrm{V} \beta 3, \alpha \mathrm{V} \beta 5, \alpha 5 \beta 1$ & Tumstatin \\
\hline $\mathrm{COX}-2$ & Platelet factor-4 (PF4) \\
\hline Histamine & Kringle 5 (plasminogen fragment) \\
\hline Plasminogen activator & Fragment of SPARC \\
\hline PIGF & Angioarrestin \\
\hline Bfrf & Restin \\
\hline IGF-i & Vasoinhibin \\
\hline
\end{tabular}

zation of different angiogenic pathways and coordination of cell-cell interactions in this process [116]. ECM has multiple components around the vessels, of which many are proteins and have stimulatory or inhibitory effects on angiogenesis [117]. The proteolytic release of matrixbound VEGF isoforms has been proved to be a substantial regulator of VEGF bioavailability and pattern of the vasculature [118]. ECM proteases such as MMP9, on the one hand, can release matrix-bound VEGF and promote angiogenesis, for example as an important phase in tumorigenesis; on the other hand, these enzymes can also suppress pro-angiogenic activities of VEGF [119]. In addition, it has been thought that physical contact between endothelial cells and pericytes may result in the induction of quiescent phenotype without sprouting of the vessels $[120,121]$.

\section{The Role of Angiogenesis in Tumor Development and Metastasis}

Several lines of experimental and clinical investiga- 
tions verify the concept that angiogenesis is a key element for invasion, progression, and metastasis of the tumors [122, 123]. Angiogenesis dependency of the tumor was confirmed by multiple pieces of evidence that indicated that tumor growth and metastasis are inhibited by anti-angiogenic factors [124, 125]. Most tumors remain in the stage, which is called carcinoma in situ, without angiogenesis for a long time. This stage is considered as a pre-cancerous neoplasm that may be terminated by vascularization of the tumor during the phase termed angiogenic switch when the tumor requires to keep growing [126]. Folkman believed that angiogenesis itself should be considered as "organizing principle", which means that there are basic connections between molecular mechanisms apparently unrelated phenomena, not as a sign of malignancy [127]. This point of view has prominent consequences for developing therapeutic approaches in cancer and other unrelated diseases, leading to a discovery in one field to be utilized to describe events in another field [128]. Although pathological dysregulation of cell cycle control was found that is the first step in the development of a tumor, it is now accepted that most of the dysregulated pathways that lead to cancer are the consequence of deregulated angiogenesis and functions of tumor vasculature [129]. Notably, the tumor vasculature may involve in the deregulated tumor metabolism, genetic instability, inflammation, and metastatic tumor growth [130, 131]. Tumors are often hypoxic and this hypoxic state results in advanced but dysfunctional vascularization and can alter different aspects of tumor metabolism [132]. Tumor-hypoxia was reported as the main cause of highly reactive oxygen species (ROS) production within the tumor cells [133] and also pathological metabolism and acidosis in the tumor tissue [134, 135]. Pathological angiogenesis of tumor, microvascular leakage and hypoxia-induced apoptosis in the central part of the tumor together lead to tremendous recruitment and activation of inflammatory cells, including macrophages, lymphocytes, neutrophils, and mast cells. These immune cells contribute to produce massive growth and pro-angiogenic factors and cytokines via communication with a complex network of signaling pathways [136-138]. The inflammatory cytokines interleukin- $1 \alpha$ and interleukin-1 $\beta$, as well as other angiogenic factors such as VEGF and MMPs, may implicate in angiogenesis, development of a tumor, and cancer metastasis [139, 140]. The deregulated tumor vasculature in relation with hypoxia can induce angiogenesis in cancer-associated fibroblasts (CAFs), which involved in the tumor progression and resistance to treatment [141]. On the other hand, these cells are rich sources of tumor angiogenic growth factors and cytokines, playing an important role in sustaining tumor angiogenesis and rendering resistance to anti-angiogenic agents [142]. Angiogenesis has a key role in tumor metastasis to the distant organ (s). In some tumor types such as neurological cancers, which mostly metastasize locally, dissemination of tumor cells often occurs through the vasculature as tumor cells intravasate into blood vessels and invade the neighboring tissue by crawling along the endothelium [143]. In addition, most malignant tumors also depend on blood vessels to spread to the distant secondary organ(s). Of note, several factors such as the origin of cells, intrinsic features of the tumor, organ tropism and circulation patterns determine not only the sites of tumor dissemination but also the temporal course and severity of metastasis to other organs [144].

\section{Factors Involved in Thyroid Cancer Angiogenesis}

It has been shown that the maintenance of thyroid vasculature is mainly regulated by several ligands and its receptors, including VEGFs and their receptors (VEGFRs), and angiopoietins (Angs) and the Tie2 receptor [145-148]. A large body of evidence indicates that alterations of such crucial factors and some of other factors and receptors could implicate in a variety of thyroid abnormalities [149-152].

\section{VEGF and VEGFR}

As mentioned earlier, there are several VEGFs and VEGFRs that each VEGF ligands bind to their specific receptor(s) [61]. It is supposed that the over-expression of VEGF is a feature of differentiated thyroid carcinomas and is related to increased growth, progression, and invasiveness of the tumor [153-156]. Hsiao, et al. reported that the A allele of $-2578 \mathrm{C} / \mathrm{A}$ SNP (single nucleotide polymorphism) in the promoter of VEGF gene may increase the risk for thyroid cancer development and regional lymph node metastasis, suggesting the role of VEGF in tumor growth and spreading, the two processes which depend on angiogenesis [157]. To evaluate the potential role of angiogenic factors in human thyroid tumor growth and spread, Bunone, et al. analyzed their expression by semiquantitative RT-PCR and immunohistochemistry in normal thyroid tissues, benign lesions, and different thyroid carcinomas [158]. They found a consistent increase in VEGF, VEGF-C, and angiopoietin-2 and in their tyrosine kinase receptors VEGFR2, VEGFR3, and Tek (TEK receptor tyrosine kinase). They also reported a strong correlation between tumor size and over-expression of VEGF and angiopoietin-2. The results of that study also showed an augmented expression of VEGF-C in lymph node invasive thyroid tumors and a reduced TSP-1 expression in 
thyroid malignancies capable of hematic metastasis. Together, these findings suggest that, in human thyroid tumors, angiogenesis factors appear implicated in neoplastic growth and aggressiveness. finally, their results are in keeping with a recent hypothesis that in the presence of VEGF, angiopoietin-2 may collaborate at the front of invading vascular sprouts, serving as an initial angiogenic signal that accompanies tumor growth [158]. De la Torre, et al. analyzed microvascular density (MVD), lymphatic vascular density (LVD), and expression of angiogenic and lymphangiogenic factors in normal thyroid, multinodular goiter (MNG), toxic multinodular goiter (TNG), Graves' hyperplasia, follicular adenoma (FA), papillary thyroid carcinoma (PTC), incidental papillary microcarcinoma (PMC), follicular carcinoma (FC) and medullary carcinoma (MC) [159]. MVD was decreased in all samples, however, LVD was increased in PTC and PMC. Moreover, the expression levels of VEGF-A and VEGF-C in thyroid cancers have been increased. However, these markers have not been correlated with the presence of multifocal disease, distant metastases at diagnosis or increased tumor size [159]. Results of another nearly similar study showed an increase in both the distribution and intensity of VEGF immunopositivity in $\mathrm{MNG}, \mathrm{FA}$ and PTC as compared with the autoimmune diseases of Graves' disease and Hashimoto's disease. The expression of VEGFR1 and VEGFR2 showed minimal variations between all samples except for Graves' disease, suggesting the importance of the up-regulation of VEGF expression rather than its receptors in these diseases. Furthermore, an increased MVD in PTC was found in comparison with normal controls. However, the authors of that study have reported no clear relationship between MVD measurement and thyroid pathology [160]. The other similar study showed a strong expression of VEGF and high MVD in differentiated malignant thyroid cancers compared to poorly differentiated thyroid tumors and other thyroid tissue samples, indicating the role of VEGF as a hypoxia-inducible angiogenic factor, which is overexpressed, concomitant with hypervascularity, in malignant thyroid tumors, which need more oxygen to proliferate, than in benign follicular tumors [161]. High levels of VEGF expression and related hypervascularity in follicular tumors have also been reported in different studies $[162,163]$. Tanaka, et al. studied the expression patterns and levels of some angiogenic and anti-angiogenic factors in PTC samples [164]. According to the results of that study, VEGF expression strongly correlated with other angiogenic factors. The cytoplasm of cancer cells stained positive for all factors. Tumor invasiveness and microvessel count (MVC) had an inverse correlation with the levels of TSP-1. The authors calculated the ratio of each angiogenic factor against TSP-1 as the antiangiogenic factor to assess the balance between angiogenic and antiangiogenic factors in the same tumor. The ratios VEGF/TSP-1, VEGF-C/TSP-1, and Ang-2/TSP-1 remarkably correlated with a higher MVC. In addition, the ratios VEGF/TSP-1 and Ang-2/TSP-1 significantly correlated with the degree of infiltration. There are also several lines of evidence indicating the role of VEGF in the induction of angiogenesis as well as the correlation between invasiveness and metastatic properties of PTCs [165-167]. Gwiezdzinska, et al. conducted a study to compare the serum VEGF concentration between patients with metastatic and non-metastatic thyroid cancer, multinodular goiter, and healthy subjects [168]. The study group consisted of 71 patients, with differentiated thyroid cancer (50 papillary, 17 follicular, and 4 oxyphilic), treated in their department during the years 2003-2006. They found that the levels of serum VEGF were remarkably higher in patients with distant metastases than those in remission or healthy patients, suggesting that it may be used as a marker of thyroid cancer with distant metastases. Bugallho, et al., however, found that serum concentration of VEGF in MTC patients were not significantly different from those found in healthy subjects and did not correlate with the extension of disease [169]. Narita, et al. also reported a decreased VEGF-D serum levels in patients with metastases of differentiated thyroid cancer, regardless of the degree of metastatic spread [170]. They suggested that it is possible that some other molecule produced by the tumor could affect the VEGF-D, which is physiologically produced from different tissues, leading to a decrease in the serum levels of VEGF-D of these patients. Capp, et al. found an overexpressed VEGF-A, VEGFR-1, and VEGFR-2 proteins in MTC lesions [171]. Accordingly, they concluded that the increased expression of these molecules might be involved in tumor progression, but this might not provide prognostic information regarding the spread or outcome of MTC [171]. Results of another study, however, showed that overexpression and activation of VEGFR2 and EGFR in MTCs is related to metastatic characteristics of the tumor [172]. It has been demonstrated that the expression of VEGF in-vitro has a correlation with in-vivo aggressiveness of the tumors, with anaplastic tumors having augmented expression of VEGF [10].

\section{Thyroid stimulating hormone}

Thyroid stimulating hormone (TSH) is a glycoprotein produced by thyrotropic cells of the anterior pituitary gland, which binds to specific cell surface receptors in the thyroid gland where it stimulates the synthesis of thyroid hormone [173]. More importantly, TSH has been 
considered as a key factor that stimulates the number, size, and activity of thyrocyte cells from which differentiated thyroid cancers arises [174]. Moreover, it has been shown that TSH stimulates thyroid cancer growth, invasion, and angiogenesis. Thus, an inevitable treatment for patients with thyroid cancer includes supraphysiologic doses of thyroid hormone analogs to suppress the TSH secretion [175]. A recent study conducted to investigate the role of TSH in PTC tumor growth, focusing on tumor microenvironment [176]. In that study, Cho, et al. implanted the tumorigenic clone of PTC cells (BHP10-3SCp) in nude mice, following recombinant human TSH (rhTSH) or saline for 3 weeks ( $n=10$ /each). Larger tumor, higher MVD and higher density of macrophages were reported in the rhTSH group compared with the saline group from day 15 to day 20. The authors also evaluated the mechanism of TSH actions on tumor angiogenesis. To meet this purpose, they treated the BHP10-3SCp cells with TSH and subsequently, measured the expression of VEGF. They showed that VEGF expressions were up-regulated by 3 -fold and 9-fold at 48 and 72 hours, respectively. The authors concluded that TSH stimulates PTC tumor growth by enhancing tumor angiogenesis and macrophage recruitment into tumor microenvironment and its action on PTC tumor angiogenesis was partly mediated by VEGF, which may be a potential therapeutic target in TSH-dependent PTC progressions [176]. Soh, et al. quantified the concentration of VEGF in conditioned medium of cultured thyroid cancer cell lines derived from PTC, FTC, MTC, and Hürthle cell carcinoma (XTC-1) as well as normal thyroid cells by means of enzyme-linked immunosorbent assay. The results showed that basal VEGF secretion was similar in normal and thyroid cancer cells, except XTC-1, which had high basal secretion. Upon TSH stimulation, all thyroid cancer cells secreted considerably higher VEGF concentrations than normal thyroid cells. According to these results, authors suggested that constitutive secretion of VEGF in some thyroid cancers is a result of TSH stimulation; thus TSH may promote the thyroid tumor growth by stimulating VEGF secretion and angiogenesis [177]. Hoffmann, et al. conducted a study to 1) assess the effect of TSH on VEGF levels as well as 2) to evaluate the TSH signal transduction of this effect, and 3) to screen other growth factors for the ability to modulate VEGF in thyroid cancer cell lines [178]. They used HTC, a follicular cancer cell line lacking endogenous TSH receptor (TSHr), its receptor positive variant (HTC TSHr), and an XTC cell line in order to achieve these goals. VEGF gene and protein expressions were analyzed after stimulation with TSH and some other growth factors. According to results of the study, TSH could induce VEGF mRNA and protein in a dose-dependent manner in HTC TSHr and XTC cells by up to $40 \%$ involving protein kinase $\mathrm{C}$ pathway. However, it appears that EGF and transforming growth factor beta (TGF- $\beta$ ) could increase the capacity of thyroid cancer cells to produce VEGF more effectively than TSH. It seems that TSH stimulation has no above-mentioned effects on serum levels of VEGF in thyroid cancer patients. Tuttle, et al. proposed that serum VEGF in patients with no evidence of disease and 48 patients with local or distant metastases would be further increased by TSH stimulation [179]. Conversely, they found that no remarkable increase in serum VEGF concentrations can be detected $72 \mathrm{~h}$ after short-term TSH stimulation with recombinant human TSH. More interestingly, some investigations show that the endogenous and exogenous TSH stimulation even can significantly decrease the serum levels of VEGF, suggesting that TSH may exert its regulatory effects via receptors located outside the thyrocytes and may exert its effects on VEGF production from tissues other than the thyroid gland, respectively $[168,180]$.

\section{Iodine}

Iodine is the key material to produce thyroid hormones (T4 and T3). Iodine is absorbed and carried in the bloodstream as iodide. Iodide is incorporated into thyrocytes by the sodium/iodide symporter (NIS). Intracellular iodide is then transported in the lumen of thyroid follicles and is oxidized by thyroid peroxidase (TPO). Finally, iodine is integrated into tyrosyl residues of thyroglobulin $(\mathrm{Tg})$, the protein upon which thyroid hormones are produced [181]. Iodine deficiency in normal thyroid has detrimental effects on thyrocytes due to the importance of this ion in thyroid hormones production. This deficiency could lead to hypothyroidism and goiter [182]. Using in-vitro models of rat and human thyroid cells, Gerard, et al. showed that iodine deficiency is associated with the release of VEGF-A via a reactive oxygen species/hypoxia-inducible factor-1 (ROS/HIF-1) related pathway [183]. Besides, deficiency of this ion also has interesting effects on thyroid cancer cells. Recent data show that iodine deficiency induces a longlasting angiogenic phenotype in thyroid cancer cell lines that occurs via VEGF induction through a pathway partially mediated by hypoxia-inducible factor-1 (HIF-1). The results of that study indicate that induction of angiogenesis in cancer cells via alternative and likely less controlled pathways could result in uncontrolled growth [184]. More recently, Craps, et al. studied the involvement of mammalian target of rapamycin (mTOR) as a positive regulator and AMP-activated protein kinase (AMPK) as a negative feedback regulator of ROS/HIF-1/VEGF pathway to describe alterations of microvasculature in iodine-deficient models, including human thyrocytes and 
two murine models of goitrogenesis: normal NMRI and RET-PTC mice (a PTC model) [185]. Iodine deficiency (ID) significantly increased the phosphorylation of ribosomal S6 kinase (p70S6K), a downstream target of mTOR, whereas rapamycin completely inhibited the IDinduced increase in p70S6K phosphorylation, thyroid blood flow, and VEGF-A expression in the RET-PTC and in-vitro models. However, these effects have not shown in NMRI model. The authors concluded that mTOR is needed for early ID-induced thyroid microvascular activation, however, AMPK negatively regulates this pathway [185]. On the other hand, excess iodine can have suppressing effects on thyroid dependent angiogenesis. Suzuki, et al., based on in-vivo studies showing that iodine in excess suppresses thyroid function and blood flow in-vivo, described the molecular mechanisms of these effects [186]. They reported that excess iodide coordinately suppresses the expression of the sodium/ iodide symporter (NIS) and VEGF genes in FRTL-5 thyroid cells. The results of this study suggest that excess iodide likely affects thyroid vascular function through VEGF molecule [186]. A few years later, Nascimento, et al. showed that inhibitory effect of excess iodine on NIS expression involves activation of phosphatidylinositol 3kinase (PI3K)/protein kinase B (Akt) signaling pathway [187].

\section{FGF and FGFR}

Fibroblast growth factors (FGFs) are a family of heparin-binding proteins that exert their effects via specific binding to their cell surface receptors (FGFRs) that are equipped with tyrosine kinase activity, leading to the growth, differentiation, and function in many cell types [188]. They also have potent angiogenic characteristics and, as such, may be pivotal in the growth of solid tumors, where a rich blood supply is necessary [189]. There are several studies showing an augmented expression of FGFs and FGFRs in thyroid tumors, linking these ligands and respective receptors to etiology and development of these type of tumors [188, 190, 191]. Basic fibroblast growth factor (bFGF) or FGF2 was shown to have a key role in the development of PTC with induction of angiogenesis as well as the proliferation of the parenchymal cells [192]. Although there is an interdependency between FGF and VEGF in many tissues, it seems reasonable that FGF alone may act as an angiogenic factor in the thyroid, with direct effects on both endothelial and follicular cell growth [10]. Pituitary tumor-transforming gene (PTTG), as an oncogene, is a multifunctional protein that plays several potential roles in tumorigenic mechanisms, including angiogenesis [193]. Boelaert, et al. described a relationship between early recurrence of thyroid cancer and PTTG expression in the original tumor suggesting the role of PTTG in the promotion of tumor growth, either directly or via stimulation of FGF-2. Consistent with this point of view is the observed association between FGF-2 expression and tumor staging at presentation, which supports a role for FGF-2 in mitogenesis and angiogenesis in thyroid tumors [194]. Interestingly, Redler, et al. observed the reduced expression of FGFR-2 in follicular adenoma and PTC samples [195]. They speculated that FGFR-2 downregulation might be an early event in thyroid carcinogenesis, supporting the potential use of this receptor as an early marker for the diagnosis of thyroid cancers. However, there are several lines of studies showing the potential use of FGFRs as therapeutic targets to cease thyroid tumor growth and spreading [196-198].

\section{Matrix metalloproteinases}

Matrix metalloproteinases (MMPs) are a group of endopeptidases which contain a zinc ion at their active site, for proteolytic activity. MMPs are produced by tumor cells and can affect tumor development in several ways, including the promotion of tumor growth, invasion and migration, angiogenesis and apoptosis inhibition. MMPs support angiogenesis by releasing pro-angiogenic factors and degrading ECM [199]. Among these proteolytic enzymes, MMP-2 and MMP-9 have been shown to have promoting effects on tumor invasion and angiogenesis by activation of TGF- $\beta$ [200]. Tissue inhibitors of metalloproteinases (TIMPs) are endogenous proteins, which are known to inhibit MMPs [201]. There are multiple investigations indicating the expression and overexpression of some MMPs and TIMPs related to the diagnosis and prognosis of thyroid cancers. For example, Cavalheiro, et al. reported that the ratio of MMP-2 to TIMP-2 expression is an important and novel prognostic factor to anticipate consequences of surgically treated MTC [202]. In another study, They also showed a significant correlation between the expression of MMP-2 and clinical characteristics of MTC patients, suggesting the use of this factor as an indicator of prognosis of this cancer [203]. Marko, et al. also reported a role for both MMP-2 and TIMP-2 in development of thyroid tumors and suggested the potential use of immunohistochemical positivity of these factors for diagnosis of PTC and prediction of the adverse behavior of the tumor [204]. Some studies revealed that overexpression of some MMPs is accompanied by an increased expression of proangiogenic factors such as VEGF and FGF, which are related to tumor growth and invasiveness [205, 206]. Table 2 shows the main factors involved in thyroid cancer angiogenesis. 
Table 2 Factors involved in thyroid cancer angiogenesis

\begin{tabular}{llcl}
\hline Factor & \multicolumn{1}{c}{ Type } & Role in thyroid cancer angiogenesis & \multicolumn{1}{c}{${\text { Effect on } \mathrm{MVD}^{\mathrm{a}}}^{\mathrm{c}}$} \\
\hline VEGF & Growth factor & Pro-angiogenic & Increase \\
\hline VEGFR & Growth factor receptor & Pro-angiogenic & Increase \\
TSH & Hormone & Pro-angiogenic & Increase \\
Iodine & Ion & Pro-angiogenic & $\mathrm{NR}^{\mathrm{b}}$ \\
FGF & Growth factor & Pro-angiogenic & $\mathrm{NR}^{\mathrm{b}}$ \\
FGFR & Growth factor receptor & Pro-angiogenic & $\mathrm{NR}^{\mathrm{b}}$ \\
MMP & Proteolytic enzyme & Pro-angiogenic & $\mathrm{NR}^{\mathrm{b}}$ \\
\hline
\end{tabular}

${ }^{a}$ MVD, microvascular density

${ }^{\mathrm{b}} \mathrm{NR}$, not reported

\section{Conclusion}

As mentioned earlier, there are several factors with some roles in the promotion of thyroid cancer angiogenesis. However, the effects of some factors on the angiogenic activity of this type of cancer are more remarkable than the others. Accordingly, VEGFs and its receptors appear to be the main role players in the angiogenesis process of thyroid tumors. Thus, other players seem to have an upstream regulatory effect on this central factor(s). However, all factors that mentioned in this review have potential to consider as suitable diagnostic, therapeutic and prognostic markers, but it is not possible to have a more comprehensive discussion on the role of these factors in thyroid cancer development and progres- sion due to lack of sufficient data on their determining role in these processes. Hence, there appears a need for more appropriate and comprehensive studies to uncover different aspects of thyroid cancer angiogenesis with the emphasis on different angiogenic and antiangiogenic factors.

\section{Conflict of Interest}

The authors have no conflict of interest.

\section{Funding}

The authors have no funding to declare.

\section{References}

1. Hsiao S, Nikiforov Y (2014) Molecular approaches to thyroid cancer diagnosis. Endocr Relat Cancer 21: T301T313.

2. Schneider DF, Mazeh H, Lubner SJ, Jaume JC, Chen H (2014) Cancer of the Endocrine System. In: Niederhuber JE, Armitage JO, Doroshow JH, Kastan MB, Tepper JE, editors. Abeloff's Clinical Oncology $\left(5^{\text {th }}\right)$. Elsevier, Philadelphia: 1112-1142.

3. Nishida N, Yano H, Nishida T, Kamura T, Kojiro M (2006) Angiogenesis in cancer. Vasc Health Risk Manag 2: $213-219$

4. Ide A, Baker N, Warren S (1939) Vascularization of the Brown-Pearce rabbit epithelioma transplant as seen in the transparent ear chamber. AJR Am J Roentgenol 42: 891899.

5. Greene HS (1941) Heterologous transplantation of mammalian tumors: II. The transfer of human tumors to alien species. J Exp Med 73: 475.

6. Ribatti D (2008) Judah Folkman, a pioneer in the study of angiogenesis. Angiogenesis 11: 3-10.

7. Zetter BR (2008) The scientific contributions of M. Judah Folkman to cancer research. Nat Rev Cancer 8: 647-654.
8. Folkman J (1990) What is the evidence that tumors are angiogenesis dependent? J Natl Cancer Inst 82: 4-6.

9. Kubis N, Levy B (2003) Vasculogenesis and angiogenesis: molecular and cellular controls: part 1: growth factors. Interv Neuroradiol 9: 227-237.

10. Ramsden J (2000) Angiogenesis in the thyroid gland. $J$ Endocrinol 166: 475-480.

11. Wehland M, Bauer J, Magnusson NE, Infanger M, Grimm D (2013) Biomarkers for anti-angiogenic therapy in cancer. Int J Mol Sci 14: 9338-9364.

12. Mashreghi M, Azarpara H, Bazaz MR, Jafari A, Masoudifar A, et al. (2018) Angiogenesis biomarkers and their targeting ligands as potential targets for tumor angiogenesis. J Cell Physiol 233: 2949-2965.

13. Darke R, Vogl AW, Mitchell AWM (2015) Gray's Anatomy. Gray's Anatomy for Students $\left(3^{\text {th }}\right)$. Elsevier, England: 966-967.

14. Hanahan D, Weinberg RA (2000) The hallmarks of cancer. Cell 100: 57-70.

15. Hanahan D, Weinberg RA (2011) Hallmarks of cancer: the next generation. Cell 144: 646-674.

16. Krishna Priya S, Nagare RP, Sneha V, Sidhanth C, 
Bindhya S, et al (2016) Tumour angiogenesis - origin of blood vessels. Int J Cancer 139: 729-735.

17. Ribatti D (2014) History of research on angiogenesis. In: Marone G, Granata F (eds). Angiogenesis, Lymphangiogenesis and Clinical Implications.

18. Breier G (2000) Angiogenesis in embryonic development - a review. Placenta 21: S11-S15.

19. Sherer D, Abulafia O (2001) Angiogenesis during implantation, and placental and early embryonic development. Placenta 22: 1-13.

20. Kurz H (2000) Physiology of angiogenesis. J Neurooncol 50: $17-35$.

21. Osório J (2014) Thyroid gland: human thyroid gland development and function - angiogenesis in the spotlight. Nat Rev Endocrinol 10: 444.

22. Korevaar TI, Steegers EA, Schalekamp-Timmermans S, Ligthart S, et al. (2014) Soluble Flt1 and placental growth factor are novel determinants of newborn thyroid (dys) function: the generation R study. J Clin Endocrinol Metab 99: E1627-E1634.

23. Siemann DW (2011) The unique characteristics of tumor vasculature and preclinical evidence for its selective disruption by tumor-vascular disrupting agents. Cancer Treat Rev 37: 63-74.

24. Bergers G, Benjamin LE (2003) Tumorigenesis and the angiogenic switch. Nat Rev Cancer 3: 401-410.

25. Hanahan D, Folkman J (1996) Patterns and emerging mechanisms of the angiogenic switch during tumorigenesis. Cell 86: 353-364.

26. Castañeda-Gill JM, Vishwanatha JK (2016) Antiangiogenic mechanisms and factors in breast cancer treatment. $J$ Carcinog 15: 1 .

27. Fox SB, Generali DG, Harris AL (2007) Breast tumour angiogenesis. Breast Cancer Res 9: 216.

28. Sprindzuk M, Dmitruk A, Kovalev V, Bogush A, Tuzikov A, et al. (2009) Computer-aided image processing of angiogenic histological. J Clin Med Res 1: 249-261.

29. Liu Q, Hu T, He L, Huang X, Tian X, et al. (2015) Genetic targeting of sprouting angiogenesis using AplnCreER. Nat Commun 6: 6020.

30. Benest AV, Augustin HG (2009) Tension in the vasculature. Nat Med 15: 608-610.

31. Shinkaruk S, Bayle M, Lain G, Deleris G (2003) Vascular endothelial cell growth factor (VEGF), an emerging target for cancer chemotherapy. Curr Med Chem Anticancer Agents 3: 95-117.

32. Gasparini G (2001) Clinical significance of determination of surrogate markers of angiogenesis in breast cancer. Crit Rev Oncol Hematol 37: 97-114.

33. Kalluri R, Sukhatme VP (2000) Fibrosis and angiogenesis. Curr Opin Nephrol Hypertens 9: 413-418.

34. Prager GW, Poettler M (2012) Angiogenesis in cancer. Basic mechanisms and therapeutic advances. Hämostaseologie 32: 105-114.

35. Hillen F, Griffioen AW (2007) Tumour vascularization: sprouting angiogenesis and beyond. Cancer Metastasis Rev 26: 489-502.

36. Caduff JH, Fischer LC, Burri PH (1986) Scanning elec- tron microscopic study of the developing microvasculature in thepostnatal rat lung. Anat Rec 216: 154-164.

37. Burri PH, Tarek MR (1990) A novel mechanism of capillary growth in the rat pulmonary microcirculation. Anat Rec 228: 35-45.

38. Burri PH, Dbaly J, Weibel ER (1974) The postnatal growth of the rat lung. I. Morphometry. Anat Rec 178: 711-730.

39. Adams RH, Alitalo K (2007) Molecular regulation of angiogenesis and lymphangiogenesis. Nat Rev Mol Cell Biol 8: 464-478.

40. Styp-Rekowska B, Hlushchuk R, Pries AR, Djonov V (2011) Intussusceptive angiogenesis: pillars against the blood flow. Acta Physiol (Oxf) 202: 213-223.

41. Kreuger J, Phillipson M (2016) Targeting vascular and leukocyte communication in angiogenesis, inflammation and fibrosis. Nat Rev Drug Discov 15: 125-142.

42. Clark ER, Clark EL (1939) Microscopic observations on the growth of blood capillaries in the living mammal. Dev Dyn 64: 251-301.

43. Gerhardt H, Golding M, Fruttiger M, Ruhrberg C, Lundkvist A, et al. (2003) VEGF guides angiogenic sprouting utilizing endothelial tip cell filopodia. $J$ Cell Biol 161: 1163-1177.

44. Isogai S, Lawson ND, Torrealday S, Horiguchi M, Weinstein BM (2003) Angiogenic network formation in the developing vertebrate trunk. Development 130: 52815290 .

45. Auerbach R, Arensman R, Kubai L, Folkman J (1975) Tumor-induced angiogenesis: lack of inhibition by irradiation. Int J Cancer 15: 241-245.

46. Adams RH, Eichmann A (2010) Axon guidance molecules in vascular patterning. Cold Spring Harb Perspect Biol 2: a001875.

47. Jakobsson L, Kreuger J, Claesson-Welsh L (2007) Building blood vessels - stem cell models in vascular biology. $J$ Cell Biol 177: 751-755.

48. Horowitz A, Simons M (2009) Branching morphogenesis. Circ Res 103: 784-795.

49. Carmeliet P, De Smet F, Loges S, Mazzone M (2009) Branching morphogenesis and antiangiogenesis candidates: tip cells lead the way. Nat Rev Clin Oncol 6: 315326.

50. Gerwins P, Sköldenberg E, Claesson-Welsh L (2000) Function of fibroblast growth factors and vascular endothelial growth factors and their receptors in angiogenesis. Crit Rev Oncol Hematol 34: 185-194.

51. Martino MM, Tortelli F, Mochizuki M, Traub S, BenDavid D, et al. (2011) Engineering the growth factor microenvironment with fibronectin domains to promote wound and bone tissue healing. Sci Transl Med 3: $100 \mathrm{ra} 89$.

52. Coussens LM, Raymond WW, Bergers G, Laig-Webster M, Behrendtsen O, et al. (1999) Inflammatory mast cells up-regulate angiogenesis during squamous epithelial carcinogenesis. Genes Dev 13: 1382-1397.

53. Weinstein BM (1999) What guides early embryonic blood vessel formation? Dev Dyn 215: 2-11. 
54. Zhong TP (2005) Zebrafish genetics and formation of embryonic vasculature. Curr Top Dev Biol 71: 53-81.

55. Chappell JC, Wiley DM, Bautch VL (2011) Regulation of blood vessel sprouting. Semin Cell Dev Biol 22: 10051011.

56. Chappell JC, Taylor SM, Ferrara N, Bautch VL (2009) Local guidance of emerging vessel sprouts requires soluble Flt-1. Dev Cell 17: 377-386.

57. Ferrara N, Gerber HP, LeCouter J (2003) The biology of VEGF and its receptors. Nat Med 9: 669-676.

58. Koch S, Claesson-Welsh L (2012) Signal transduction by vascular endothelial growth factor receptors. Cold Spring Harb Perspect Med 2: a006502.

59. Goel HL, Mercurio AM (2013) VEGF targets the tumour cell. Nat Rev Cancer 13: 871-882.

60. Koch S (2012) Neuropilin signalling in angiogenesis. Biochem Soc Trans 40: 20-25.

61. Lange C, Storkebaum E, De Almodóvar CR, Dewerchin M, Carmeliet P (2016) Vascular endothelial growth factor: a neurovascular target in neurological diseases. Nat Rev Neuro 12: 439-454.

62. Gerber HP, Ferrara N (2003) The role of VEGF in normal and neoplastic hematopoiesis. J Mol Med (Berl) 81: 2031.

63. Avraham-Davidi I, Yona S, Grunewald M, Landsman L, Cochain C, et al. (2013) On-site education of VEGFrecruited monocytes improves their performance as angiogenic and arteriogenic accessory cells. J Exp Med 210: 2611-2625.

64. Cursiefen C, Chen L, Borges LP, Jackson D, Cao J, et al. (2004) VEGF-A stimulates lymphangiogenesis and hemangiogenesis in inflammatory neovascularization via macrophage recruitment. J Clin Invest 113: 1040-1050.

65. Ruiz de Almodovar C, Lambrechts D, Mazzone M, Carmeliet P (2009) Role and therapeutic potential of VEGF in the nervous system. Physiol Rev 89: 607-648.

66. Moens S, Goveia J, Stapor PC, Cantelmo AR, Carmeliet P (2014) The multifaceted activity of VEGF in angiogenesis -implications for therapy responses. Cytokine Growth Factor Rev 25: 473-482.

67. Ferrara N, Adamis AP (2016) Ten years of anti-vascular endothelial growth factor therapy. Nat Rev Drug Discov 15: 385-403.

68. Ruhrberg C, Gerhardt H, Golding M, Watson R, Ioannidou S, et al. (2002) Spatially restricted patterning cues provided by heparin-binding VEGF-A control blood vessel branching morphogenesis. Genes Dev 16: 2684 2698.

69. Gerhardt H (2008) VEGF and endothelial guidance in angiogenic sprouting. Organogenesis 4: 241-246.

70. Taylor CJ, Church JE, Williams MD, Gerrand YW, Keramidaris E, et al. (2017) Hypoxic preconditioning of myoblasts implanted in a tissue engineering chamber significantly increases local angiogenesis via upregulation of myoblast VEGF-A expression, and downregulation of miRNA-1, miRNA-206 and Angiopoietin 1. J Tissue Eng Regen Med 12: e408-e421.

71. Lobov I, Renard R, Papadopoulos N, Gale N, Thurston G, et al. (2007) Delta-like ligand 4 (D114) is induced by VEGF as a negative regulator of angiogenic sprouting. Proc Natl Acad Sci U S A 104: 3219-3224.

72. Hellström M, Phng LK, Hofmann JJ, Wallgard E, Coultas L, et al. (2007) Dll4 signalling through Notch1 regulates formation of tip cells during angiogenesis. Nature 445: 776-780.

73. Suchting S, Freitas C, Le Noble F, Benedito R, Bréant C, et al. (2007) The notch ligand delta-like 4 negatively regulates endothelial tip cell formation and vessel branching. Proc Natl Acad Sci U S A 104: 3225-3230.

74. De Spiegelaere W, Casteleyn C, Van Den Broeck W, Plendl J, Bahramsoltani M, et al. (2012) Intussusceptive angiogenesis: a biologically relevant form of angiogenesis. J Vasc Res 49: 390-404.

75. Burri PH, Djonov V (2002) Intussusceptive angiogenesis -the alternative to capillary sprouting. Mol Aspects Med 23: S1-S27.

76. Caduff J, Fischer L, Burri PH (1986) Scanning electron microscope study of the developing microvasculature in the postnatal rat lung. Anat Rec 216: 154-164.

77. Kurz H, Burri PH, Djonov VG (2003) Angiogenesis and vascular remodeling by intussusception: from form to function. News Physiol Sci 18: 65-70.

78. Burri PH, Hlushchuk R, Djonov V (2004) Intussusceptive angiogenesis: its emergence, its characteristics, and its significance. Dev Dyn 231: 474-488.

79. Andres AC, Djonov V (2010) The mammary gland vasculature revisited. J Mammary Gland Biol Neoplasia 15: 319-328.

80. Patan S, Alvarez MJ, Schittny JC, Burri PH (1992) Intussusceptive microvascular growth: a common alternative to capillary sprouting. Arch Histol Cytol 55: 65-75.

81. Macchiarelli G, Jiang JY, Nottola SA, Sato E (2006) Morphological patterns of angiogenesis in ovarian follicle capillary networks. A scanning electron microscopy study of corrosion cast. Microsc Res Tech 69: 459-468.

82. Hirschberg RM, Plendl J (2005) Pododermal angiogenesis and angioadaptation in the bovine claw. Microsc Res Tech 66: 145-155.

83. Egginton S, Zhou AL, Brown MD, Hudlicka O (2001) Unorthodox angiogenesis in skeletal muscle. Cardiovasc Res 49: 634-646.

84. De Spiegelaere W, Cornillie P, Erkens T, Van Loo D, Casteleyn C, et al. (2010) Expression and localization of angiogenic growth factors in developing porcine mesonephric glomeruli. J Histochem Cytochem 58: 1045-1056.

85. De Spiegelaere W, Cornillie P, Casteleyn C, Burvenich C, Van Den Broeck W (2010) Detection of hypoxia inducible factors and angiogenic growth factors during foetal endochondral and intramembranous ossification. Anat Histol Embryol 39: 376-384.

86. Djonov V, Andres AC, Ziemiecki A (2001) Vascular remodelling during the normal and malignant life cycle of the mammary gland. Microsc Res Tech 52: 182-189.

87. Patan S, Munn LL, Jain RK (1996) Intussusceptive microvascular growth in a human colon adenocarcinoma xenograft: a novel mechanism of tumor angiogenesis. 
Microvasc Res 51: 260-272.

88. Nico B, Crivellato E, Guidolin D, Annese T, Longo V, et al. (2010) Intussusceptive microvascular growth in human glioma. Clin Exp Med 10: 93-98.

89. Heindryckx F, Mertens K, Charette N, Vandeghinste B, Casteleyn C, et al. (2010) Kinetics of angiogenic changes in a new mouse model for hepatocellular carcinoma. $\mathrm{Mol}$ Cancer 9: 219.

90. Hlushchuk R, Riesterer O, Baum O, Wood J, Gruber G, et al. (2008) Tumor recovery by angiogenic switch from sprouting to intussusceptive angiogenesis after treatment with PTK787/ZK222584 or ionizing radiation. $A m J$ Pathol 173: 1173-1185.

91. Hlushchuk R, Makanya AN, Djonov V (2011) Escape mechanisms after antiangiogenic treatment, or why are the tumors growing again? Int J Dev Biol 55: 563-567.

92. Makanya AN, Stauffer D, Ribatti D, Burri PH, Djonov V (2005) Microvascular growth, development, and remodeling in the embryonic avian kidney: the interplay between sprouting and intussusceptive angiogenic mechanisms. Microsc Res Tech 66: 275-288.

93. Makanya AN, Hlushchuk R, Baum O, Velinov N, Ochs M, et al. (2007) Microvascular endowment in the developing chicken embryo lung. Am J Physiol Lung Cell Mol Physiol 292: L1136-L1146.

94. Boerckel JD, Uhrig BA, Willett NJ, Huebsch N, Guldberg RE (2011) Mechanical regulation of vascular growth and tissue regeneration in vivo. Proc Natl Acad Sci U S A 108: E674-E680.

95. Kilarski WW, Samolov B, Petersson L, Kvanta A, Gerwins P (2009) Biomechanical regulation of blood vessel growth during tissue vascularization. Nat Med 15: 657-664.

96. Kilarski WW, Gerwins P (2009) A new mechanism of blood vessel growth-hope for new treatment strategies. Discov Med 8: 23-27.

97. Valluru M, Brown NJ, Cross SS, Reed MW, Staton CA (2011) Blood vessel characterization in human dermal wound repair and scarring. Br J Dermatol 165: 221-224.

98. Maes C, Kobayashi T, Selig MK, Torrekens S, Roth S, et al. (2010) Osteoblast precursors, but not mature osteoblasts, move into developing and fractured bones along with invading blood vessels. Dev Cell 19: 329-344.

99. Dvorak HF (1986) Tumors: wounds that do not heal. Similarities between tumor stroma generation and wound healing. N Engl J Med 315: 1650-1659.

100. Mayer A, Höckel M, Horn LC, Schmidberger H, Vaupel P (2011) GLUT-1 staining of squamous cell carcinomas of the uterine cervix identifies a novel element of invasion. Int J Oncol 38: 145-150.

101. Vakoc BJ, Lanning RM, Tyrrell JA, Padera TP, Bartlett LA, et al. (2009) Three-dimensional microscopy of the tumor microenvironment in vivo using optical frequency domain imaging. Nat Med 15: 1219-1223.

102. Pandya NM, Dhalla NS, Santani DD (2006) Angiogenesis -a new target for future therapy. Vascul Pharmacol 44: 265-274.

103. Yoo SY, Kwon SM (2013) Angiogenesis and its therapeu- tic opportunities. Mediators Inflamm 2013: 127170.

104. Huang Z, Bao SD (2004) Roles of main pro-and antiangiogenic factors in tumor angiogenesis. World J Gastroenterol 10: 463-470.

105. Dameron KM, Volpert OV, Tainsky MA, Bouck N (1994) Control of angiogenesis in fibroblasts by $\mathrm{p} 53$ regulation of thrombospondin-1. Science 265: 1582-1584.

106. Scarpino S, Di Napoli A, Taraboletti G, Cancrini A, Ruco LP (2005) Hepatocyte growth factor (HGF) downregulates thrombospondin 1 (TSP-1) expression in thyroid papillary carcinoma cells. J Pathol 205: 50-56.

107. Okada F, Rak JW, Croix BS, Lieubeau B, Kaya M, et al. (1998) Impact of oncogenes in tumor angiogenesis: mutant K-ras up-regulation of vascular endothelial growth factor/vascular permeability factor is necessary, but not sufficient for tumorigenicity of human colorectal carcinoma cells. Proc Natl Acad Sci U S A 95: 3609-3614.

108. Meng F, Ding J, Liu N, Zhang J, Shao X, et al. (2005) Inhibition of gastric cancer angiogenesis by vector-based RNA interference for Raf-1. Cancer Biol Ther 4: 113-117.

109. Sounni NE, Roghi C, Chabottaux V, Janssen M, Munaut C, et al. (2004) Up-regulation of VEGF-A by active MT1MMP through activation of Src-tyrosine kinases. $J$ Biol Chem 279: 13564-13574.

110. Yu D, Hung MC (2000) Overexpression of ErbB2 in cancer and ErbB2-targeting strategies. Oncogene 19: 61156521.

111. Iliopoulos O, Levy AP, Jiang C, Kaelin WG, Goldberg MA (1996) Negative regulation of hypoxia-inducible genes by the von Hippel-Lindau protein. Proc Natl Acad Sci U S A 93: 10595-10599.

112. Sundaram P, Hultine S, Smith LM, Dews M, Fox JL, et al. (2011) p53-responsive miR-194 inhibits thrombospondin-1 and promotes angiogenesis in colon cancers. Cancer Res 71: 7490-7501.

113. Adams RH, Alitalo K (2007) Molecular regulation of angiogenesis and lymphangiogenesis. Nat Rev Mol Cell Biol 8: 464-478.

114. Mahabeleshwar GH, Chen J, Feng W, Somanath PR, Razorenova OV, et al. (2008) Integrin affinity modulation in angiogenesis. Cell Cycle 7: 335-347.

115. Mahabeleshwar GH, Feng W, Reddy K, Plow EF, Byzova TV (2007) Mechanisms of integrin-vascular endothelial growth factor receptor cross-activation in angiogenesis. Circ Res 101: 570-580.

116. Murakami M, Simons M (2008) Fibroblast growth factor regulation of neovascularization. Curr Opin Hematol 15: 215-220.

117. Nyberg P, Xie L, Kalluri R (2005) Endogenous inhibitors of angiogenesis. Cancer Res 65: 3967-3979.

118. Lee S, Jilani SM, Nikolova GV, Carpizo D, Iruela-Arispe ML (2005) Processing of VEGF-A by matrix metalloproteinases regulates bioavailability and vascular patterning in tumors. J Cell Biol 169: 681-691.

119. Vempati P, Popel AS, Mac Gabhann F (2014) Extracellular regulation of VEGF: isoforms, proteolysis, and vascular patterning. Cytokine Growth Factor Rev 25: 1-19.

120. Bergers G, Song S (2005) The role of pericytes in blood- 
vessel formation and maintenance. Neuro Oncol 7: 452 464.

121. Armulik A, Abramsson A, Betsholtz C (2005) Endothelial/pericyte interactions. Circ Res 97: 512-523.

122. Martin TA, Ye L, Sanders AJ, Lane J, Jiang WG (2013) Cancer invasion and metastasis: molecular and cellular perspective. In: Rahul J (ed). Metastatic Cancer Clinical and Biological Perspectives, Landes Bioscience, Austin, TX: 135-168.

123. Salehi B, Zucca P, Sharifi-Rad M, Pezzani R, Rajabi S, et al. (2018) Phytotherapeutics in cancer invasion and metastasis. Phytother Res 32: 1425-1449.

124. Kubota Y (2012) Tumor angiogenesis and anti-angiogenic therapy. Keio J Med 61: 47-56.

125. Cao Y (2016) Future options of anti-angiogenic cancer therapy. Chin J Cancer 35: 21.

126. Bielenberg DR, Zetter BR (2015) The contribution of angiogenesis to the process of metastasis. Cancer $J$ 21: 267-273.

127. Folkman J (2007) Is angiogenesis an organizing principle in biology and medicine? J Pediatr Surg 42: 1-11.

128. Folkman J (2007) Angiogenesis: an organizing principle for drug discovery? Nat Rev Drug Discov 6: 273-286.

129. Gupta SC, Kim JH, Prasad S, Aggarwal BB (2010) Regulation of survival, proliferation, invasion, angiogenesis, and metastasis of tumor cells through modulation of inflammatory pathways by nutraceuticals. Cancer Metastasis Rev 29: 405-434.

130. Seyfried TN, Shelton LM (2010) Cancer as a metabolic disease. Nutr Metab (Lond) 7: 7.

131. Palumbo A Jr, Da Costa Nde O, Bonamino MH Pinto LFR, Nasciutti LE (2015) Genetic instability in the tumor microenvironment: a new look at an old neighbor. $\mathrm{Mol}$ Cancer 14: 145.

132. Muz B, De La Puente P, Azab F, Azab AK (2015) The role of hypoxia in cancer progression, angiogenesis, metastasis, and resistance to therapy. Hypoxia (Auckl) 3: 8392.

133. Guzy RD, Schumacker PT (2006) Oxygen sensing by mitochondria at complex III: the paradox of increased reactive oxygen species during hypoxia. Exp Physiol 91: 807-819.

134. Denko NC (2008) Hypoxia, HIF1 and glucose metabolism in the solid tumour. Nat Rev Cancer 8: 705-713.

135. Gillies RJ, Verduzco D, Gatenby RA (2012) Evolutionary dynamics unifies carcinogenesis and cancer therapy. Nat Rev Cancer 12: 487-493.

136. Bergers G, Hanahan D (2008) Modes of resistance to antiangiogenic therapy. Nat Rev Cancer 8: 592-603.

137. Ferrara N (2010) Role of myeloid cells in vascular endothelial growth factor-independent tumor angiogenesis. Curr Opin Hematol 17: 219-224.

138. Mishra AP, Salehi B, Sharifi-Rad M, Pezzani R, Kobarfard F, et al. (2018) Programmed cell death, from a cancer perspective: an overview. Mol Diagn Ther 22: 281-295.

139. Esquivel-Velázquez M, Ostoa-Saloma P, Palacios-Arreola MI, Nava-Castro KE, Castro JI, et al. (2015) The role of cytokines in breast cancer development and progression. $J$ Interferon Cytokine Res 35: 1-16.

140. Apte RN, Krelin Y, Song X, Dotan S, Recih E, et al. (2006) Effects of micro-environment-and malignant cellderived interleukin-1 in carcinogenesis, tumour invasiveness and tumour-host interactions. Eur J Cancer 42: 751759.

141. De Francesco EM, Lappano R, Santolla MF, Marsico S, Caruso A, et al. (2013) HIF-1 $\alpha /$ GPER signaling mediates the expression of VEGF induced by hypoxia in breast cancer associated fibroblasts (CAFs). Breast Cancer Res 15: R64.

142. Shiga K, Hara M, Nagasaki T, Sato T, Takahashi H, et al. (2015) Cancer-associated fibroblasts: their characteristics and their roles in tumor growth. Cancers (Basel) 7: 24432458.

143. Ricci-Vitiani L, Pallini R, Biffoni M, Todaro M, Invernici $\mathrm{G}$, et al. (2010) Tumour vascularization via endothelial differentiation of glioblastoma stem-like cells. Nature 468: 824-828.

144. Nguyen DX, Bos PD, Massagué J (2009) Metastasis: from dissemination to organ-specific colonization. Nat Rev Cancer 9: 274-284.

145. Augustin HG, Koh GY, Thurston G, Alitalo K (2009) Control of vascular morphogenesis and homeostasis through the angiopoietin-Tie system. Nat Rev Mol Cell Biol 10: 165-177.

146. Carmeliet P (2003) Angiogenesis in health and disease. Nat Med 9: 653-660.

147. Chung AS, Ferrara N (2011) Developmental and pathological angiogenesis. Annu Rev Cell Dev Biol 27: 563584.

148. Lohela M, Bry M, Tammela T, Alitalo K (2009) VEGFs and receptors involved in angiogenesis versus lymphangiogenesis. Curr Opin Cell Biol 21: 154-165.

149. Nagura S, Katoh R, Miyagi E, Shibuya M, Kawaoi A (2001) Expression of vascular endothelial growth factor (VEGF) and VEGF receptor-1 (Flt-1) in Graves disease possibly correlated with increased vascular density. Hum Pathol 32: 10-17.

150. Ramsden JD, Buchanan MA, Egginton S, Watkinson JC, Mautner V, et al. (2005) Complete inhibition of goiter in mice requires combined gene therapy modification of angiopoietin, vascular endothelial growth factor, and fibroblast growth factor signaling. Endocrinology 146: 2895-2902.

151. Davies TF, Ando T, Lin RY, Tomer Y, Latif R (2005) Thyrotropin receptor-associated diseases: from adenomata to Graves disease. J Clin Invest 115: 1972-1983.

152. Jang JY, Choi SY, Park I, Park DY, Choe K, et al. (2017) VEGFR2 but not VEGFR3 governs integrity and remodeling of thyroid angiofollicular unit in normal state and during goitrogenesis. EMBO Mol Med 9: 750-769.

153. Sherman SI, Wirth LJ, Droz JP, Hofmann M, Bastholt L, et al. (2008) Motesanib diphosphate in progressive differentiated thyroid cancer. $N$ Engl J Med 359: 31-42.

154. Soh EY, Duh QY, Sobhi SA, Young DM, Epstein HD, et al. (1997) Vascular endothelial growth factor expression is 
higher in differentiated thyroid cancer than in normal or benign thyroid. J Clin Endocrinol Metab 82: 3741-3747.

155. Lin JD, Chao TC (2005) Vascular endothelial growth factor in thyroid cancers. Cancer Biother Radiopharm 20: 648-661.

156. Lewy-Trenda I, Wierzchniewska-Ławska A (2001) Expression of vascular endothelial growth factor (VEGF) in human thyroid tumors. Pol J Pathol 53: 129-132.

157. Hsiao PJ, Lu MY, Chiang FY, Shin SJ, Tai YD, et al. (2007) Vascular endothelial growth factor gene polymorphisms in thyroid cancer. $J$ Endocrinol 195: 265-270.

158. Bunone G, Vigneri $\mathrm{P}$, Mariani L, Butó S, Collini $\mathrm{P}$, et al. (1999) Expression of angiogenesis stimulators and inhibitors in human thyroid tumors and correlation with clinical pathological features. The Am J Pathol 155: 1967-1976.

159. de la Torre NG, Buley I, Wass JA, Turner HE (2006) Angiogenesis and lymphangiogenesis in thyroid proliferative lesions: relationship to type and tumour behaviour. Endocr Relat Cancer 13: 931-944.

160. Jebreel AE, England J, Bedford K, Murphy J, Karsai L, et al. (2007) Vascular endothelial growth factor (VEGF), VEGF receptors expression and microvascular density in benign and malignant thyroid diseases. Int $J$ Exp Pathol 88: 271-277.

161. Itoh A, Iwase $\mathrm{K}$, Jimbo S, Yamamoto $\mathrm{H}$, Yamamoto $\mathrm{N}$, et al. (2010) Expression of vascular endothelial growth factor and presence of angiovascular cells in tissues from different thyroid disorders. World J Surg 34: 242-248.

162. Giatromanolaki A, Lyberakidis G, Lyratzopoulos N, Koukourakis MI, Sivridis E, et al. (2010) Angiogenesis and angiogenic factor expression in thyroid cancer. $J$ BUON 15: 357-361.

163. Huang SM, Lee JC, Wu TJ, Chow NH (2001) Clinical relevance of vascular endothelial growth factor for thyroid neoplasms. World J Surg 25: 302-306.

164. Tanaka K, Sonoo H, Kurebayashi J, Nomura T, Ohkubo S, et al. (2002) Inhibition of infiltration and angiogenesis by thrombospondin-1 in papillary thyroid carcinoma. Clin Cancer Res 8: 1125-1131.

165. Scarpino S, D'Alena FC, Di Napoli A, Ballarini F, Prat M, et al. (2003) Papillary carcinoma of the thyroid: evidence for a role for hepatocyte growth factor (HGF) in promoting tumour angiogenesis. $J$ Pathol 199: 243-250.

166. Kilicarslan AB, Ogus M, Arici C, Pestereli HE, Cakir M, et al. (2003) Clinical importance of vascular endothelial growth factor (VEGF) for papillary thyroid carcinomas. APMIS 111: 439-443.

167. Lennard CM, Patel A, Wilson J, Reinhardt B, Tuman C, et al. (2001) Intensity of vascular endothelial growth factor expression is associated with increased risk of recurrence and decreased disease-free survival in papillary thyroid cancer. Surgery 129: 552-558.

168. Klubo-Gwiezdzinska J, Junik R, Kopczynska E, Juraniec O, Kardymowicz H (2007) The comparison of serum vascular endothelial growth factor levels between patients with metastatic and non-metastatic thyroid cancer, and patients with nontoxic multinodular goiter. Eur J Endocrinol 157: 521-527.
169. Bugalho MJ, Madureira D, Espadinha C, Font AP, Sobrinho LG (2008) Serum vascular endothelial growth factor levels in patients with medullary thyroid carcinoma. Eur J Endocrinol 159: 167-169.

170. Nersita R, Matrone A, Klain M, Scavuzzo F, Vitolo G, et al. (2012) Decreased serum vascular endothelial growth factor-D levels in metastatic patients with differentiated thyroid carcinoma. Clin Endocrinol (Oxf) 76: 142-146.

171. Capp C, Wajner SM, Siqueira DR, Brasil BA, Meurer L, et al. (2010) Increased expression of vascular endothelial growth factor and its receptors, VEGFR-1 and VEGFR-2, in medullary thyroid carcinoma. Thyroid 20: 863-871.

172. Rodríguez-Antona C, Pallares J, Montero-Conde C, Inglada-Pérez L, Castelblanco E, et al. (2010) Overexpression and activation of EGFR and VEGFR2 in medullary thyroid carcinomas is related to metastasis. Endocr Relat Cancer 17: 7-16.

173. Sarapura VD, Gordon D, Samuels MH (2011) Thyroidstimulating Hormone. The Pituitary. Elsevier, England: 167-203.

174. Freudenthal B, Williams GR (2017) Thyroid stimulating hormone suppression in the long-term follow-up of differentiated thyroid cancer. Clin Oncol (R Coll Radiol) 29: 325-328.

175. Jin J, Machekano R, Mchenry CR (2010) The utility of preoperative serum thyroid-stimulating hormone level for predicting malignant nodular thyroid disease. Am J Surg 199: 294-298.

176. Cho SW, Shong YS, Sun HJ, Park DJ, Yi KH, et al. (2016) Thyroid stimulating hormone promotes tumor growth by modulating angiogenesis and macrophage recruitment in papillary thyroid cancer microenvironment. Thyroid Hormone Action, Cancer and Clinical Thyroid. Endocrine Society OR11-3 (Absract).

177. Soh EY, Sobhi SA, Wong MG, Meng Y, Siperstein A, et al. (1996) Thyroid-stimulating hormone promotes the secretion of vascular endothelial growth factor in thyroid cancer cell lines. Surgery 120: 944-947.

178. Hoffmann S, Hofbauer LC, Scharrenbach V, Wunderlich A, Hassan I, et al. (2004) Thyrotropin (TSH)-induced production of vascular endothelial growth factor in thyroid cancer cells in vitro: evaluation of TSH signal transduction and of angiogenesis-stimulating growth factors. J Clin Endocrinol Metab 89: 6139-6145.

179. Tuttle R, Fleisher M, Francis GL, Robbins RJ (2002) Serum vascular endothelial growth factor levels are elevated in metastatic differentiated thyroid cancer but not increased by short-term TSH stimulation. J Clin Endocrinol Metab 87: 1737-1742.

180. Sorvillo F, Mazziotti G, Carbone A, Piscopo M, Rotondi M, et al. (2003) Recombinant human thyrotropin reduces serum vascular endothelial growth factor levels in patients monitored for thyroid carcinoma even in the absence of thyroid tissue. J Clin Endocrinol Metab 88: 4818-4822.

181. Rousset B, Dupuy C, Miot F, Dumont F (2000) Chapter 2. Thyroid hormone synthesis and secretion. [Updated 2015 Sep 2]. In: Feingold KR, Anawalt B, Boyce A, et al., editors. Endotext [Internet]. South Dartmouth (MA). 
182. Zimmermann MB, Jooste PL, Pandav CS (2008) Iodinedeficiency disorders. Lancet 372: 1251-1262.

183. Gérard AC, Poncin S, Audinot JN, Denef JF, Colin IM (2009) Iodide deficiency-induced angiogenic stimulus in the thyroid occurs via HIF-and ROS-dependent VEGF-A secretion from thyrocytes. Am J Physiol Endocrinol Metab 296: E1414-E1422.

184. Gérard AC, Humblet K, Wilvers C, Poncin S, Derradji H, et al. (2012) Iodine-deficiency-induced long lasting angiogenic reaction in thyroid cancers occurs via a vascular endothelial growth factor-hypoxia inducible factor-1dependent, but not a reactive oxygen species-dependent, pathway. Thyroid 22: 699-708.

185. Craps J, Joris V, De Jongh B, Sonveaux P, Horman S, et al. (2016) Involvement of mTOR and regulation by AMPK in early iodine deficiency-induced thyroid microvascular activation. Endocrinology 157: 2545-2559.

186. Suzuki K, Kimura H, Wu H, Kudo N, Kim WB, et al. (2010) Excess iodide decreases transcription of NIS and VEGF genes in rat FRTL-5 thyroid cells. Biochem Biophys Res Commun 393: 286-290.

187. Serrano-Nascimento C, Da Silva Teixeira S, Nicola JP, Nachbar RT, Masini-Repiso AM, et al. (2014) The acute inhibitory effect of iodide excess on sodium/iodide symporter expression and activity involves the PI3K/Akt signaling pathway. Endocrinology 155: 1145-1156.

188. Eggo MC, Hopkins JM, Franklyn JA, Johnson GD, Sanders DS, et al. (1995) Expression of fibroblast growth factors in thyroid cancer. J Clin Endocrinol Metab 80: 1006-1011.

189. Cross MJ, Claesson-Welsh L (2001) FGF and VEGF function in angiogenesis: signalling pathways, biological responses and therapeutic inhibition. Trends Pharmacol Sci 22: 201-207.

190. Shingu K, Fujimori M, Ito K, Hama Y, Kasuga Y, et al. (1998) Expression of fibroblast growth factor-2 and fibroblast growth factor receptor-1 in thyroid diseases. Endocr $J$ 45: 35-43.

191. Thompson SD, Franklyn JA, Watkinson JC, Verhaeg JM, Sheppard MC, et al. (1998) Fibroblast growth factors 1 and 2 and fibroblast growth factor receptor 1 are elevated in thyroid hyperplasia. J Clin Endocrinol Metab 83: 1336 1341.

192. Daa T, Kodama M, Kashima K, Yokoyama S, Nakayama I, et al. (1993) Identification of basic fibroblast growth factor in papillary carcinoma of the thyroid. Acta Pathol Jpn 43: 582-589.

193. Kim DS, Franklyn JA, Stratford AL, Boelaert K, Watkinson JC, et al. (2006) Pituitary tumor-transforming gene regulates multiple downstream angiogenic genes in thyroid cancer. J Clin Endocrinol Metab 91: 1119-1128.

194. Boelaert K, McCabe CJ, Tannahill LA, Gittoes NJ, Holder RL, et al. (2003) Pituitary tumor transforming gene and fibroblast growth factor-2 expression: potential prognostic indicators in differentiated thyroid cancer. $J$ Clin Endocrinol Metab 88: 2341-2347.

195. Redler A, Di Rocco G, Giannotti D, Frezzotti F, Bernieri MG, et al. (2013) Fibroblast growth factor receptor-2 expression in thyroid tumor progression: potential diagnostic application. PLoS One 8: e72224.

196. Tohyama O, Matsui J, Kodama K, Hata-Sugi N, Kimura $\mathrm{T}$, et al. (2014) Antitumor activity of lenvatinib (e7080): an angiogenesis inhibitor that targets multiple receptor tyrosine kinases in preclinical human thyroid cancer models. J Thyroid Res 2014: 638747.

197. Lorusso L, Pieruzzi L, Biagini A, Sabini E, Valerio L, et al. (2016) Lenvatinib and other tyrosine kinase inhibitors for the treatment of radioiodine refractory, advanced, and progressive thyroid cancer. Onco Targets Ther 9: 64676477.

198. Ezzat S, Huang P, Dackiw A, Asa SL (2005) Dual inhibition of RET and FGFR4 restrains medullary thyroid cancer cell growth. Clin Cancer Res 11: 1336-1341.

199. Fink K, Boratyński J (2012) The role of metalloproteinases in modification of extracellular matrix in invasive tumor growth, metastasis and angiogenesis. Postepy Hig Med Dosw (Online) 66: 609-628 (In Polish).

200. Yu Q, Stamenkovic I (2000) Cell surface-localized matrix metalloproteinase- 9 proteolytically activates TGF- $\beta$ and promotes tumor invasion and angiogenesis. Genes Dev 14: 163-176.

201. Murphy G (2011) Tissue inhibitors of metalloproteinases. Genome Biol 12: 233.

202. Cavalheiro BG, Junqueira CR, Brandão LG (2009) Ratio of metalloproteinase 2 to tissue inhibitor of metalloproteinase 2 in medullary thyroid carcinoma. Arch Otolaryngol Head Neck Surg 135: 812-817.

203. Cavalheiro BG, Junqueira CR, Brandao LG (2008) Expression of matrix metalloproteinase 2 (MMP-2) and tissue inhibitor of metalloproteinase 2 (TIMP-2) in medullary thyroid carcinoma: prognostic implications. Thyroid 18: 865-871.

204. Mareĉko I, Cvejić D, Tatić S, Dragutinović V, Paunović I, et al. (2012) Expression of matrix metalloproteinase-2 and its tissue inhibitor-2 in fetal and neoplastic thyroid tissue and their significance as diagnostic and prognostic markers in papillary carcinoma. Cancer Biomark 11: 49-58.

205. Komorowski J, Pasieka Z, Jankiewicz-Wika J, Stepień H (2002) Matrix metalloproteinases, tissue inhibitors of matrix metalloproteinases and angiogenic cytokines in peripheral blood of patients with thyroid cancer. Thyroid 12: 655-662.

206. Lin SY, Wang YY, Sheu WHH (2003) Preoperative plasma concentrations of vascular endothelial growth factor and matrix metalloproteinase 9 are associated with stage progression in papillary thyroid cancer. Clin Endocrinol (Oxf) 58: 513-518. 